\title{
BMJ Open Ketamine for the treatment of prehospital acute pain: a systematic review of benefit and harm
}

\author{
Mårten Sandberg, ${ }^{1,2}$ Per Kristian Hyldmo, ${ }^{3,4,5}$ Poul Kongstad, ${ }^{6}$ \\ Kristian Dahl Friesgaard, ${ }^{7,8}$ Lasse Raatiniemi (1) , 9,10 Robert Larsen, ${ }^{11,12}$ \\ Vidar Magnusson, ${ }^{13}$ Leif Rognås (1) , ${ }^{14,15,16}$ Jouni Kurola, ${ }^{17,18}$ Marius Rehn (1) , ${ }^{1,3,4}$ \\ Gunn Elisabeth Vist ${ }^{19}$
}

To cite: Sandberg M, Hyldmo PK, Kongstad P, et al. Ketamine for the treatment of prehospital acute pain: a systematic review of benefit and harm. BMJ Open 2020;10:e038134. doi:10.1136/ bmjopen-2020-038134

- Prepublication history and additional material for this paper is available online. To view these files, please visit the journal online (http://dx.doi.org/10. 1136/bmjopen-2020-038134).

Received 28 February 2020 Revised 19 September 2020 Accepted 30 October 2020

Check for updates

(C) Author(s) (or their employer(s)) 2020. Re-use permitted under CC BY-NC. No commercial re-use. See rights and permissions. Published by BMJ.

For numbered affiliations see end of article.

Correspondence to

Dr Marius Rehn;

rehmar@snla.no

\section{ABSTRACT}

Background Few publications have addressed prehospital use of ketamine in analgesic doses. We aimed to assess the effect and safety profile of ketamine compared with other analgesic drugs (or no drug) in adult prehospital patients with acute pain.

Methods A systematic review of clinical trials assessing prehospital administration of ketamine in analgesic doses compared with other analgesic drugs or no analgesic treatment in adults. We searched PubMed, EMBASE, Cochrane Library and Epistemonikos from inception until 15 February 2020, including relevant articles in English and Nordic languages. We used the Cochrane and Grading of Recommendations Assessment, Development and Evaluation methodologies and exclusively assessed patient-centred outcomes. Two independent authors screened trials for eligibility, extracted data and assessed risk of bias.

Results We included eight studies (2760 patients). Ketamine was compared with various opioids given alone, and intranasal ketamine given with nitrous oxide was compared with nitrous oxide given alone. Four randomised controlled trials (RCTs) and one cluster randomised trial included 699 patients. One prospective cohort included 27 patients and two retrospective cohorts included 2034 patients. Five of the eight studies had high risks of bias. Pain score with ketamine is probably lower than after opioids as demonstrated in a cluster-RCT (308 patients) and a retrospective cohort (158 patients) study, $\Delta$ visual analogue scale $-0.4(-0.8$ to 0.0$)$ and $\Delta$ numeric pain rating scale $-3.0(-3.86$ to -2.14$)$, respectively. Ketamine probably leads to less nausea and vomiting (risk ratio (RR) 0.24 (0.11 to 0.52 )) but more agitation (RR 7.81 (1.85 to 33)) than opioids.

Conclusions This systematic literature review finds that ketamine probably reduces pain more than opioids and with less nausea and vomiting but higher risk of agitation. Risk of bias in included studies is high.

Other Scandinavian society of anaesthesiology and intensive care medicine funded meetings and software. The Norwegian Air Ambulance Foundation funded publication. Otherwise this research received no grant from any agency in the public, commercial or not-for-profit sectors.

PROSPERO registration number CRD42018114399.
Strengths and limitations of this study

- A systematic review where main outcomes were assessed according to the Grading of Recommendations Assessment, Development and Evaluation method.

- Studies were heterogeneous in terms of setting, patient population, outcomes and comparators.

- Only English-language and Scandinavian-language articles were included.

\section{INTRODUCTION}

Prehospital acute pain is a frequent symptom and often inadequately managed. ${ }^{1-3}$ Several analgesics are administered by prehospital emergency medical services throughout the world without solid evidence of their efficacy and safety. The heterogeneity in pain management strategies may reflect the varying competence levels of providers ranging from technicians with basic training to specially trained physicians. Opioids are most frequently used, but their cerebral, haemodynamic and respiratory side effects remain a potential challenge in unstable and undifferentiated prehospital patients. ${ }^{4}$ Ketamine is an alternative to opioids. Ketamine exerts its effects mainly as an N-methyl-D-aspartate antagonist and, depending on the dose, can be considered as an analgesic, a sedative or an anaesthetic drug. ${ }^{5}$ One attractive feature for prehospital use of ketamine is its ability to preserve upper airway reflexes. Respiratory rate may increase, and ketamine can cause bronchodilation. While ketamine generally preserves respiratory function, ketamine can cause respiratory depression if given quickly. ${ }^{6}$ There is a risk of laryngospasm, which may require intubation in a very small fraction of cases. $^{7}$

Ketamine can be administered in a variety of routes, most commonly intramuscularly, 
intranasally and intravenously, although per oral and per rectal doses are used in different settings. Although originally believed to cause an increase in intracranial pressure (ICP), recent work in critical care patients indicates that ketamine has little or no impact on ICP. In two studies comparing ketamine and sufentanil, the authors concluded that ketamine did not affect ICP and that it was safe to administer to patients with traumatic brain injury (TBI) ${ }^{89}$ In another study, ketamine in conjunction with propofol was administered to patients with TBI, and a significant decrease in ICP was recorded.${ }^{10}$ In one study on children with TBI, a reduction in ICP by up to $30 \%$ was found, and cerebral perfusion was improved. ${ }^{11}$ In these studies, ketamine was used in anaesthetic doses, and the results should be interpreted with caution.

Moderate or severe agitation occurs in 5\%-30\% of adult patients; some clinicians administer boluses of midazolam to avoid this phenomenon. ${ }^{6}$ A randomised controlled trial (RCT) showed that this practice significantly reduced agitation in adults; however, one trial found that it did not reduce agitation in children. ${ }^{6} 12$

Proper pain relief allows prehospital care providers to meet essential clinical endpoints, for example, facilitating fracture manipulation. Although analgesia should be titrated for the desired effect, pain relief is frequently suboptimal, possibly due to concerns about adverse events. ${ }^{13}$ Ketamine may be a useful prehospital analgesic mainly due to its ability to provide excellent analgesic effects with a lower incidence of respiratory depression than that caused by opioids. These positive effects have been demonstrated in fracture management, ${ }^{14}$ burn treatment ${ }^{15}$ and traumatic amputation. ${ }^{16}$

The aim of this systematic literature review is to explore the benefit and harm of ketamine compared with other analgesic drugs (or no drug) in prehospital patients with acute pain.

\section{METHODS}

We conducted this systematic review according to the Cochrane Handbook for systematic reviews of interventions ${ }^{17}$ and as described in our protocol as specified below.

\section{Inclusion criteria}

We used the following inclusion criteria:

\section{Population}

Adult patients (18 years of age or older) with acute pain in the prehospital setting

\section{Intervention}

Ketamine

\section{Comparison}

Other analgesics, no analgesics or ketamine given in another dose or another route of administration or ketamine given in combination with other analgesics

\section{Outcomes}

Pain reduction, speed of onset, duration of effect and relevant adverse events such as mortality, morbidity, anaphylaxis, nausea and vomiting, hypotension, respiratory failure, loss of airway patency, emergence phenomena (as defined by study authors).

We included all adult patients (18 years of age or older) with acute pain, regardless of aetiology, managed in the prehospital setting. We also sought to identify adverse effects that are not previously reported. The following study designs were considered eligible for inclusion in the meta-analysis: RCTs, non-randomised controlled studies, cohort studies with a control group, interrupted time series and controlled before-and-after studies. Case series were also included for information relating to safety. Systematic reviews of high-quality answering to our inclusion criteria were evaluated for eligible studies. Other systematic reviews would have been used to check for relevant references.

\section{Exclusion criteria}

Children (younger than 18 years of age) and patients with chronic pain and/or patients who used ketamine as part of their regular treatments were not included in this review. We excluded all studies that were not conducted in the prehospital setting as well as conference abstracts, letters and publications without full texts available.

\section{Search strategy}

An experienced research librarian in collaboration with the authors developed the search strategy based on the inclusion criteria. The following databases were searched from their inception: PubMed, EMBASE, Cochrane Library and Epistemonikos.

The most recent search was conducted on 15 February 2020 , and the full search strategy is presented in online supplemental appendix 1 . The search was limited to the following languages: Danish, English, Finnish, Icelandic, Norwegian and Swedish.

The reference lists of the included publications were checked in order to identify relevant articles not found in the original search.

\section{Study selection}

For each step in the review process, no assessor handled publications they had coauthored. MS and either PKH, MR or PK independently assessed all titles and abstracts identified from the search according to the inclusion criteria above. References that were considered potentially relevant were collected, and the full-text articles were assessed independently by two assessors using the same inclusion criteria. Any disagreement between the initial two assessors was discussed and resolved by all assessors. The process of study selection based on titles and abstracts, study selection based on full-text articles and risk of bias assessments were conducted using Covidence (Covidence systematic review software, Veritas Health 
Innovation, Melbourne, Australia. Available at www.covidence.org).

\section{Assessment of risk of bias}

MS and either PKH, MR or PK independently assessed the risk of bias for each of the included studies in accordance with the recommendations by the Cochrane Collaboration. ${ }^{17}$ For RCTs, the following items were assessed for risk of bias: (1) sequence generation, (2) concealment of allocation, (3) blinding of participants and personnel, (4) blinding of outcome assessor, (5) incomplete outcome data, (6) selective outcome reporting and (7) other risk of bias. For non-RCTs and other studies with a control group, the following items were also assessed for risk of bias: (8) similarity of baseline characteristics, (9) similarity of baseline outcome data and (10) contamination. All items were rated as either high, unclear or low risk of bias.

\section{Data extraction}

MS and either PKH or PK independently extracted data from each included study. We extracted data pertaining to full references; study design and country in which the study was conducted; characteristics of the population, for example, number of patients; age; gender; cause of pain; setting and context; type and dose of analgesics given; cadre/competency of the healthcare personnel who administered the analgesic; comparison/control intervention; attrition; outcomes and follow-up times. We did not contact any study investigators to obtain information not described in the original articles.

The process of study selection based on titles and abstracts, study selection based on full-text articles as well as risk of bias assessments were conducted using Covidence.

\section{Statistical analysis}

Dichotomous outcomes are presented as risk ratios (RRs) with $95 \%$ CIs. Continuous outcomes are presented as the mean difference between the groups with $95 \%$ CIs. If different scales were used to measure the same outcome, we would have calculated standardised mean difference with a 95\% CI. We used Review Manager (RevMan V.5.3) software to generate forest plots. Attrition was handled using intention-to-treat analysis. We evaluated statistical heterogeneity using the $Q$ test and $\mathrm{I}^{2}$-statistic. Analysis was by inverse variance and random effects methods. Zero events were presented descriptively.

\section{Grading our confidence in the evidence}

We assessed our confidence in the evidence for each outcome using the Grading of Recommendations

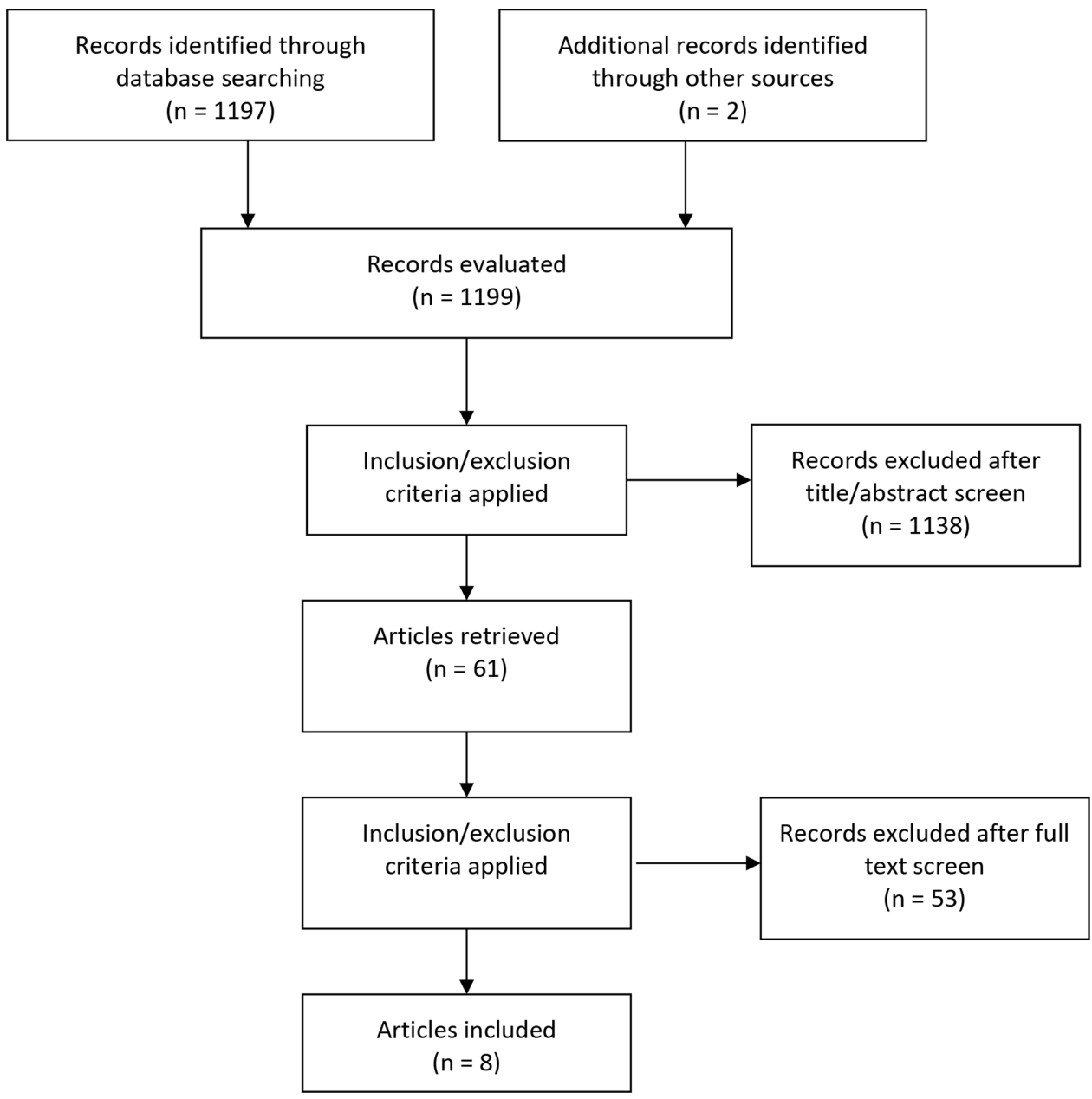

Figure 1 Flow diagram of evaluated records. 


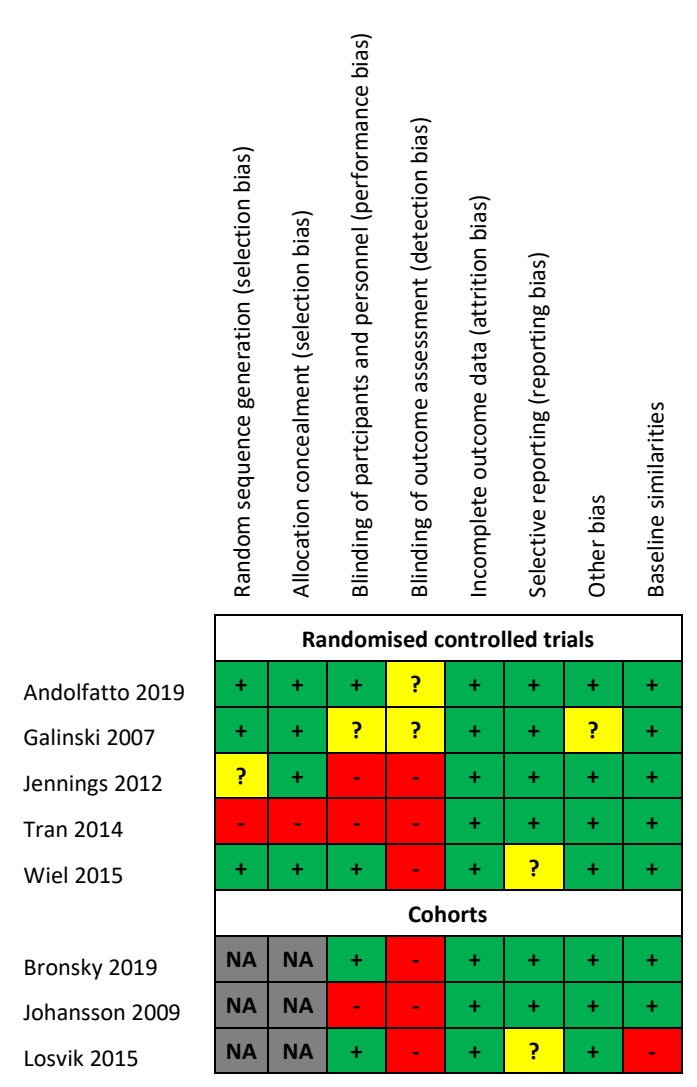

Figure 2 Risk of bias.

Assessment, Development and Evaluation (GRADE) method. ${ }^{18}$ Our confidence is presented as high, moderate, low or very low. The evidence across each outcome is assessed by eight criteria. Five criteria lowered our confidence in the evidence: (1) risk of bias/methodological limitations, (2) consistency between studies (statistical heterogeneity), (3) directness (similar study participants, intervention, comparator and outcome measures in the included studies to the population and target interventions and measures), (4) precision of results and (5) reporting bias. Three criteria were used to consider upgrading evidence from observational studies that had not been downgraded: (1) strong or very strong association between intervention and outcome,; (2) large or very large dose response and (3) situations where all plausible confounders would have reduced the effect. For questions about the effect of interventions, RCTs started at high confidence, and observational studies started at low confidence.

\section{Breach of protocol}

We did make a breach of protocol; the largest study (Losvik et al) we included also contained treatment data from a few children. ${ }^{19}$

\section{Patient and public involvement}

The development of the research question and outcome measures were informed by studies indicating that prehospital acute pain is a frequent symptom and often inadequately managed. ${ }^{1-3}$ No patients were directly involved in the design or conduct of this study.

The results will be disseminated as a part of a Scandinavian society of anaesthesiology and intensive care medicine guideline on prehospital pain management.

\section{RESULTS}

The systematic literature search identified 1197 references; we considered 60 to be potentially relevant and assessed those publications in full. We included seven of these studies in the final analysis. In addition, two unique references in the reference lists of the seven publications were assessed and one of the references was also included. Figure 1 shows the flow diagram of the identified references. The 53 studies that were assessed in full-text articles and excluded are presented in online supplemental appendix 2 with the reason for their exclusion.

\section{Characterisation of the trials}

The eight included studies were conducted in Australia, ${ }^{20}$ Canada, ${ }^{21}$ France, ${ }^{22}{ }^{23}$ Iraq, ${ }^{19}$ Sweden, ${ }^{24}$ USA $^{25}$ and Vietnam. ${ }^{26}$ A total of 2760 prehospital patients with acute pain were included in these eight studies. Four RCTs ${ }^{20-23}$ and one cluster randomised trial ${ }^{26}$ included 699 patients. One prospective cohort study ${ }^{24}$ included 27 patients. Two retrospective cohort studies ${ }^{19}{ }^{25}$ included 2034 patients. The largest of these studies, with 1876 patients, was conducted in the war zones and mine fields of northern and central Iraq. ${ }^{19}$ Two authors stated that their studies were conducted in rural areas, with one in Australia and one in Vietnam. The latter study included areas with mine fields, and three patients had been involved in mine accidents. This study also included children; however, the vast majority of included patients was probably adults because the mean ages of the groups were 35.5 years and 36.9 years. Therefore, this study was included. The reported time frame was similar in all studies; that is, from drug administration to admission to hospital.

\section{Risk of bias assessment}

Our assessments regarding each bias domain are provided in figure 2. Three of the five RCTs had a high risk of bias, with the main reasons being lack of random sequence generation, lack of allocation concealment or lack of blinding of patients, personnel and outcome assessors.

\section{Comparisons}

The included studies covered five comparisons involving ketamine (table 1):

- Ketamine intravenous versus opioids (morphine, ${ }^{26}$ fentanyl ${ }^{25}$ pentazocine ${ }^{19}$ ) intravenous.

- Ketamine intravenous and morphine intravenous versus only morphine intravenous. ${ }^{202324}$

- Ketamine intravenous given as continuous administration versus ketamine intravenous as single dose. ${ }^{22}$

- Ketamine intranasally and nitrous oxide versus only nitrous oxide. $^{21}$ 
Table 1 Summary of included studies

\section{Reference \\ Study design \\ Country}

Ketamine

Comparison

Outcomes

Ketamine intravenous vs opioids intravenous

Retrospective cohort intravenous every $20 \mathrm{~min}$ as

USA

needed, maximum three doses

$\begin{array}{ll}\text { Losvik et } \mathrm{al}^{19} 2015 & \mathrm{n}=713, \text { ketamine } 0.2 \mathrm{mg} / \mathrm{kg} \\ \text { Retrospective cohort } & \text { intravenous, in case of unrest, } \\ \text { Iraq } & 5 \mathrm{mg} \text { diazepam intravenous. } \\ & \text { During protracted evacuations } \\ & \text { with repeated ketamine doses, } \\ & 1 \mathrm{mg} \text { atropine was administered. } \\ & \text { Repeat doses of ketamine } \\ & \text { allowed. }\end{array}$

Tran et $a l^{26} 2014$

Cluster-RCT

$\mathrm{n}=169$, ketamine 0.2 to $0.3 \mathrm{mg} /$

$\mathrm{kg}$ was administered as slow

Vietnam
Bronsky et al ${ }^{25} 2019 \quad \mathrm{n}=79$, ketamine $0.3 \mathrm{mg} / \mathrm{kg}$ $\mathrm{n}=79$, fentanyl $2 \mu \mathrm{g} / \mathrm{kg}$ bolus intravenous over 1 to 2 min with additional dose every $10 \mathrm{~min}$ as needed

\section{$\mathrm{n}=888$, pentazocine $0.4 \mathrm{mg} / \mathrm{kg}$} intravenous for adults, repeat doses allowed
Change in pain scores, serious adverse events, GCS

Change in physiological severity score

$\mathrm{n}=139$, morphine administered in one single i.m. dose; $10 \mathrm{mg}$ for intermittent intravenous injections adult patients, $5 \mathrm{mg}$ for paediatric patients

$\mathrm{n}=32$, morphine $3 \mathrm{mg}$ intravenous every $5 \mathrm{~min}$ if necessary

Change in pain score, adverse events intravenous in $3 \mathrm{mg}$ morphine every $5 \mathrm{~min}$ if necessary

France

Jennings et $a l^{20} 2012$

RCT

$\mathrm{n}=70$, morphine $5 \mathrm{mg}$ intravenous initial dose followed by a ketamine bolus of 10 or $20 \mathrm{mg}$ according to body size, followed by $10 \mathrm{mg}$ ketamine every $3 \mathrm{~min}$ thereafter until pain was relieved

Johansson et al ${ }^{24} 2009$

$\mathrm{n}=16$, morphine $0.1 \mathrm{mg} / \mathrm{kg}$ intravenous followed by ketamine $0.2 \mathrm{mg} / \mathrm{kg}$ if pain score $\geq 4$ after 5 min $\mathrm{n}=65$, morphine $5 \mathrm{mg}$ intravenous initial dose followed by $5 \mathrm{mg}$ intravenous every 5 min until pain was relieved
Change in pain score, serious adverse events, adverse events, satisfaction, mean treatment time (head trauma)
Prospective cohort

Sweden

$\mathrm{n}=11, \mathrm{mg} / \mathrm{kg}$ morphine $0.1 \mathrm{mg} / \mathrm{kg}$

Change in pain score, adverse

$0.1 \mathrm{mg} / \mathrm{kg}$ if pain score $\geq 4$ after 5 min

Ketamine continuous intravenous administration vs ketamine intravenous one dose

\section{Wiel et al ${ }^{22} 2015 \quad \mathrm{n}=30$, all patients received $\mathrm{n}=33$, all patients received a}

$\mathrm{RCT}$

France ketamine $0.2 \mathrm{mg} / \mathrm{kg}$ intravenous bolus combined with morphine ketamine $0.2 \mathrm{mg} / \mathrm{kg} / \mathrm{h}$. Additional by a saline infusion of the same morphine $0.05 \mathrm{mg} / \mathrm{kg}$ was allowed volume. Additional morphine every 5 min if VAS $>3 / 10$
$0.05 \mathrm{mg} / \mathrm{kg}$ was allowed every $5 \mathrm{~min}$ if the VAS $>3 / 10$ event, mean treatment time

Change in pain score, adverse events, GCS

Change in pain score, adverse events, satisfaction

Intranasal ketamine and inhaled nitrous oxide vs only inhaled nitrous oxide

\begin{tabular}{|c|c|c|c|}
\hline $\begin{array}{l}\text { Andolfatto et } a l^{21} 2019 \\
\text { RCT } \\
\text { Canada }\end{array}$ & $\begin{array}{l}\mathrm{n}=60 \text {, all patients received } \\
\text { approximately } 0.75 \mathrm{mg} / \mathrm{kg} \\
\text { intranasal ketamine }(30 \mathrm{mg} \\
\text { for patients }<50 \mathrm{~kg}, 50 \mathrm{mg} \text { for } \\
\text { patients } 50-100 \mathrm{~kg}, 75 \mathrm{mg} \text { for } \\
\text { patients }>100 \mathrm{~kg}) \text { combined with } \\
\text { inhaled nitrous oxide }\end{array}$ & $\begin{array}{l}\mathrm{n}=60 \text {, all patients received inhaled } \\
\text { nitrous oxide }\end{array}$ & $\begin{array}{l}\text { Change in pain score, adverse } \\
\text { events, satisfaction }\end{array}$ \\
\hline \multicolumn{4}{|c|}{ Ketamine intravenous vs no analgesic treatment } \\
\hline $\begin{array}{l}\text { Losvik et al }{ }^{19} 2015 \\
\text { Retrospective cohort } \\
\text { Iraq }\end{array}$ & $\begin{array}{l}\mathrm{n}=713 \text {, ketamine } 0.2 \mathrm{mg} / \mathrm{kg} \\
\text { intravenous, in case of unrest, } \\
5 \mathrm{mg} \text { diazepam intravenous. } \\
\text { During protracted evacuations } \\
\text { with repeated ketamine doses, } \\
1 \mathrm{mg} \text { atropine was administered. } \\
\text { Repeat doses of ketamine } \\
\text { allowed. }\end{array}$ & $\mathrm{n}=275$, no analgesic treatment & $\begin{array}{l}\text { Change in physiological severity } \\
\text { score }\end{array}$ \\
\hline
\end{tabular}

GCS, Glasgow coma scale; VAS, visual analogue scale. 


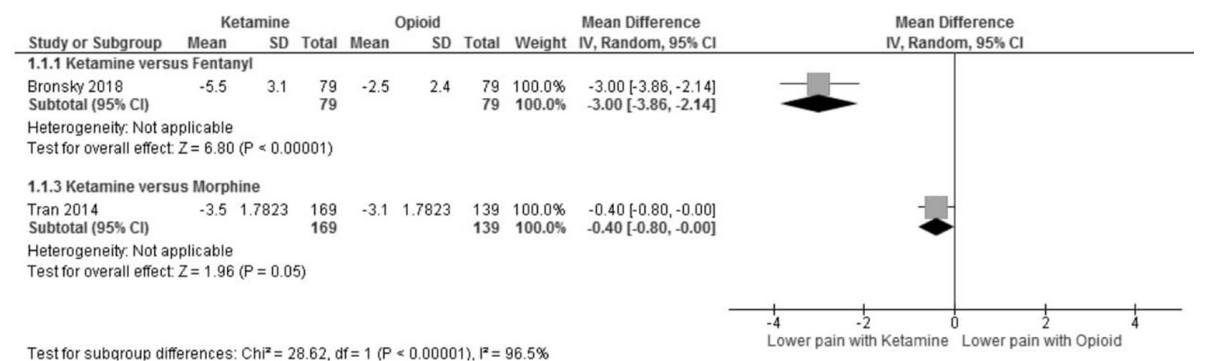

Figure 3 Ketamine versus opioids - change in pain score.

- Ketamine intravenous versus no analgesia/no medication $^{19}$

In table 1, we give a short description of the included studies and the doses used, while the excluded studies are presented with the reason for their exclusion in online supplemental appendix 2. One study contributed to two comparisons ${ }^{19}$ meaning that 713 patients who received ketamine are compared two times, first with patients who received opioids and again with patients who did not receive analgesic treatment.

\section{Ketamine versus opioids}

A change in pain score was reported in two studies. Bronsky et $a l^{25}$ used the numeric pain rating scale (NRS), where 1 represents no pain and 10 represents extreme pain, while Tran $e t a l^{26}$ measured the change in pain using the visual analogue scale (VAS) but did not explicitly give a range. Figure 3 shows that both studies reported a greater reduction in pain scores with ketamine than with the opioids fentanyl (Mean Difference (MD) -3.0 (95\% CI -3.86 to 2.14$)$ ) and morphine (MD -0.4 (95\% CI -0.08 to 0.0$)$ ).

The main outcome in the study by Losvik $e t a l^{19}$ was the physiological severity score (PSS). The PSS was calculated from the blood pressure, respiratory rate and consciousness level. ${ }^{27}$ They reported exactly the same change, at 1.5 (95\% CI 1.4 to 1.6), in the PSS for both the ketamine and the pentazocine groups. Hence, no difference was found between the treatment groups.

Adverse events were reported in the Vietnamese study ${ }^{26}$; fewer patients with nausea and vomiting were found in the ketamine group than in the morphine group and fewer patients with agitation were found in the morphine group than in the ketamine group (figure 4).
In the study where ketamine and fentanyl were compared, ${ }^{25}$ four adverse events were reported: two patients experienced respiratory compromise and two patients suffered haemodynamic instability. All four patients were in the fentanyl group.

The change in Glasgow coma scale (GCS) was measured by Bronsky $e t a l^{25}$ and found to be similar for ketamine and fentanyl, MD -0.13 (95\% CI -0.33 to 0.07$)$.

\section{Ketamine and morphine versus only morphine}

Changes in the pain scores were measured in both the Australian $^{20}$ and in the Swedish study ${ }^{24}$ using a scale from 1 to 10 where 10 represented extreme pain. In the French study, ${ }^{23}$ a scale from 0 to 100 was used, and we have transferred this to a 0 to 10 scale in order to include this study in the meta-analysis. Figure 5 shows the change in the pain score when prehospital patients received both ketamine and morphine compared with patients who received only morphine. Although the RCT performed by Jennings $e t a t^{20}$ found lower pain scores in patients receiving combined ketamine and morphine than in patients receiving only morphine. When combined with the RCT by Galinski et $a l^{23}$ the meta-analysis shows a nonsignificant reduction (MD -1.51 (95\% CI -3.36 to 0.33)) in pain score. The small prospective cohort ${ }^{28}$ also found a non-significant reduction (MD -1.30 (95\% CI -2.95 to $0.35)$ ) in pain score.

Adverse events were measured in both studies, and the results are illustrated in figure 6. It is important to note that the nausea and vomiting are included in the total adverse events in the RCTs. These results are characterised by few events but indicate that morphine alone may lead to fewer adverse events than the combination of ketamine and morphine.

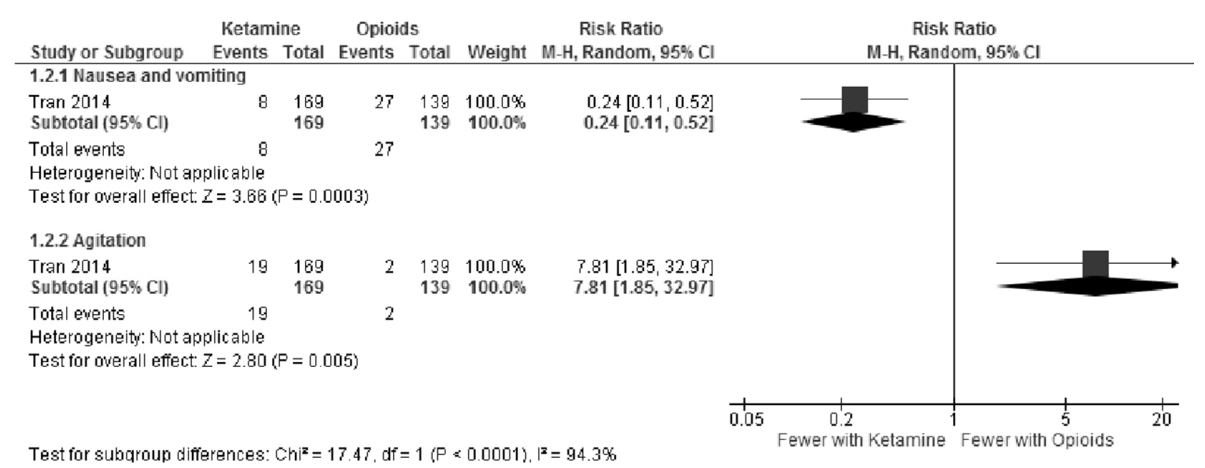

Figure 4 Ketamine versus opioids-adverse events. 


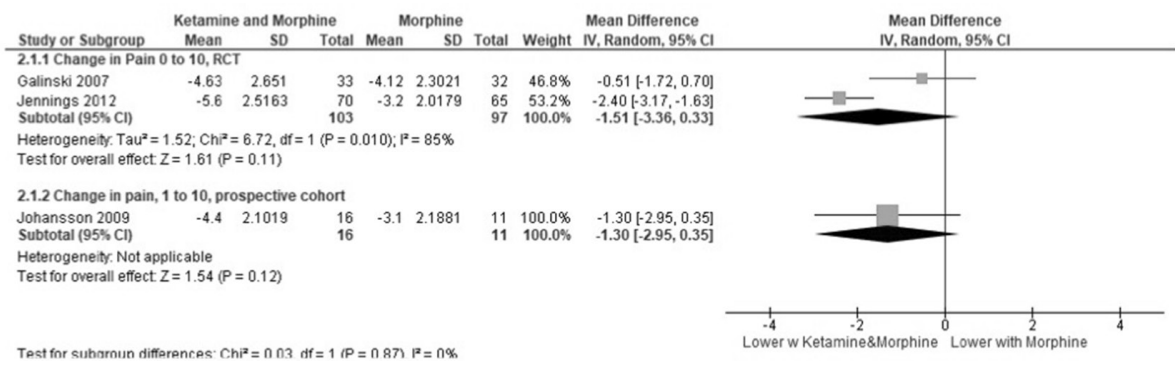

Figure 5 Combined ketamine and morphine compared with only morphine-change in pain score.

The RCT by Jennings $e t a l^{20}$ measured the GCS score and found that the median score was unchanged between initial assessment and the follow-up time, with a median score of 15 for both groups.

The French RCT reported use of fewer boluses of morphine when combined with ketamine (1 bolus $(95 \%$ CI 0 to 2) compared with 2.3 boluses (95\% CI 1.8 to 3.8 ) when using morphine alone). ${ }^{22}$

The Swedish, prospective cohort by Johansson et $a t^{28}$ reported a non-significant trend for shorter treatment time with morphine alone than with ketamine and morphine combined (10 min (95\% CI -1.4 to 21.4)). Ketamine was administered nasally, thereby avoiding the need for intravenous access.

\section{Continuous ketamine administration versus ketamine given as a}

bolus

One multicentre RCT conducted in France compared the continuous administration of ketamine with a bolus dose of ketamine but both groups also received morphine. ${ }^{22}$ Changes in pain were measured using a VAS from 0 to 10 (worst) and were similar in both groups (VAS - 0.6 (95\% CI -1.84 to 0.64$)$ ).

The main outcome of this study was the amount of additional morphine used $(\mathrm{mg} / \mathrm{kg})(\mathrm{p}=0.18)$, indicating that there was no difference between the continuous group, at 0.048 (first quartile, third quartile $0.000,0.150$ ), and the bolus group, at 0.107 (first quartile, third quartile 0.052 , 0.150 ). The duration of care for both groups was $35 \mathrm{~min}$. Nausea and vomiting were not reported in patients in the continuous group but were reported in three patients in the bolus group.

Ketamine and nitrous oxide versus only nitrous oxide

Andolfatto et al used a verbal NRS pain score and evaluated the scores after $15 \mathrm{~min}$ and $30 \mathrm{~min}^{21}$ More patients in the ketamine and nitrous oxide group had a reduction in pain of 2 or more points than those in the saline and nitrous oxide group at both time points (figure 7 ).

They reported no serious adverse effects in either group, but a considerable number of minor adverse events, such as feeling of unreality, dizziness, nausea, fatigue, general discomfort, mood change, hallucination, change in hearing and headache, occurred. Most of these side effects (52 of 66 events) were reported in the group of patients who received ketamine and nitrous oxide combined, as shown in figure 8 .

\section{Ketamine versus no analgesic treatment}

The retrospectively matched observational study of patients/causalities in the war zone in Iraq compared the use of ketamine with no analgesic treatment. ${ }^{19}$ The main outcome in this study was the PSS, which was calculated from the blood pressure, respiratory rate and consciousness level. There was a non-significant trend for lower PSS with ketamine compared with no analgesics (MD -0.2 (95\% CI -0.42 to 0.02$)$ ).

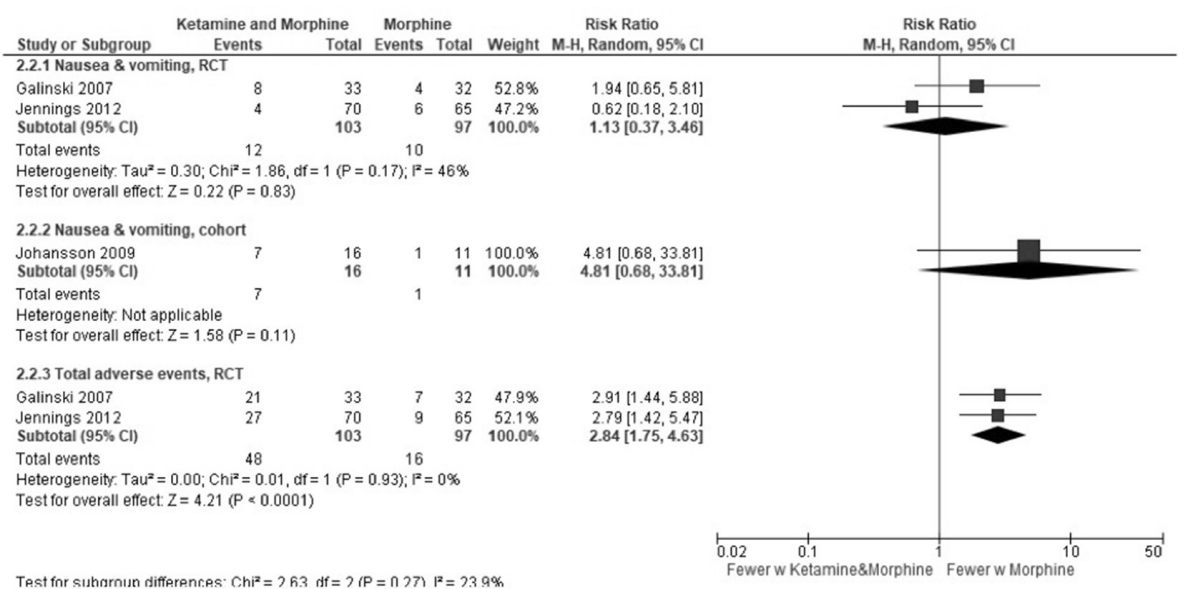

Figure 6 Combined ketamine and morphine compared with only morphine-adverse events. 


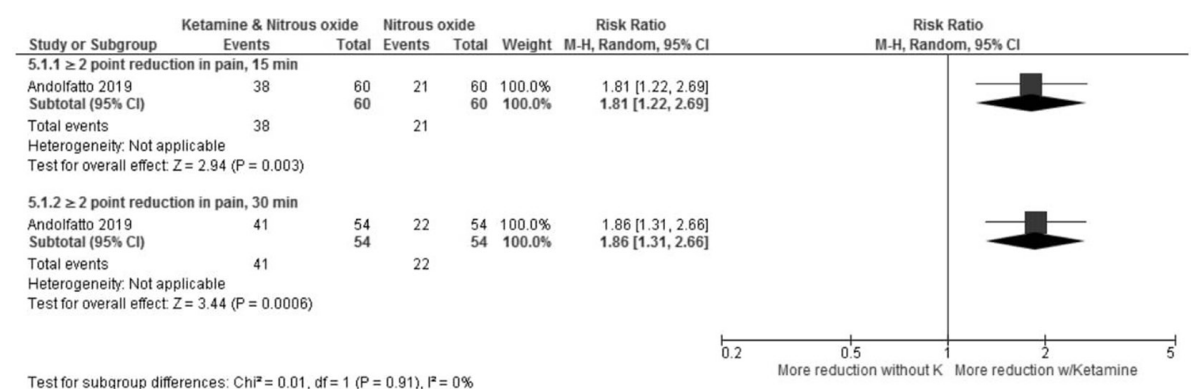

Adverse events from ketamine across the five comparisons

Seven of the eight studies reported on adverse events and/or side effects from use of ketamine. Five studies reported on nausea and vomiting from ketamine alone $(8 / 169),{ }^{26}$ from ketamine continuous administration $(0 / 30),{ }^{22}$ from ketamine bolus administration $(3 / 33)^{22}$ and from combined ketamine and morphine $(8 / 33),{ }^{23}$ $(4 / 70),{ }^{20}(7 / 16) .{ }^{24}$ Time for administering each bolus was not reported. Only one study reported on agitation, from ketamine alone $(19 / 169) .{ }^{26}$ Four studies reported adverse events, and two stated that nausea and vomiting were included as adverse events, from ketamine and morphine $(21 / 33),{ }^{23}(27 / 70) .{ }^{20}$ One study reported adverse events from ketamine and nitrous oxide $(52 / 60)^{21}$ and one study reported no adverse events from ketamine alone $(0 / 79) .{ }^{25}$

\section{GRADE}

The quality of the main outcomes for the comparisons involving the use of ketamine for the treatment of prehospital acute pain was assessed according to the GRADE method. $^{18}$ The quality of evidence could be downgraded for various reasons (risk of bias, inconsistency, indirectness, imprecision and publication bias). Consequently, the quality of the evidence was classified as high, moderate, low or very low. As described in table 2, we have for many of these outcomes downgraded for study limitations/high risk of bias or for imprecision because there were few events in many of these studies.

\section{DISCUSSION}

In this systematic review addressing the effect and safety of prehospital administration of ketamine in analgesic doses, we included eight studies with 2760 patients in total.

\section{Strengths and limitations of this systematic review}

The included studies were heterogeneous in terms of setting, patient population and outcomes explored as well as in their comparators, such as intravenous or intranasal ketamine with a variety of opioids or with nitrous oxide. In addition, a single dose of ketamine was compared with ketamine that was administered continuously.

Although the evidence base includes five RCTs, five of the eight included studies have a high risk of bias. The RCTs were relatively small studies with 63, 65, 120, 135 and 308 patients included, respectively. None of the studies was designed or powered to truly test the safety of ketamine. Adverse events and the severity thereof were inconsistently reported.

The eight studies cover five different comparisons, so the amount of research evidence for each comparison is sparse. Only one of the outcomes in one of the comparisons has been measured in more than one study of similar design, and several of the outcomes have not been assessed in a prehospital study at all. When using GRADE to assess our confidence in the estimates, we more often than not, downgraded for high risk of bias or imprecision due to very few events or wide CIs. Three of the eight included studies are observational studies. They have an initial high risk of bias compared with RCTs due to the lack of randomisation. This is acknowledged in GRADE where observational studies start at low quality of evidence. Lack of blinding is a weakness in all of these studies. This becomes a challenge when the main outcome is subjective, pain, and we have downgraded for

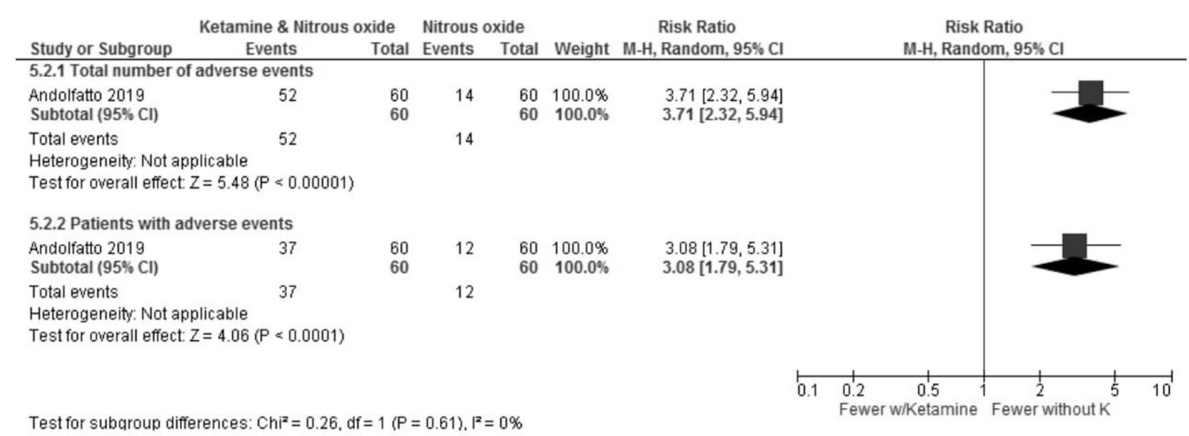

Figure 8 Ketamine and N2O versus only N2O-adverse events. 


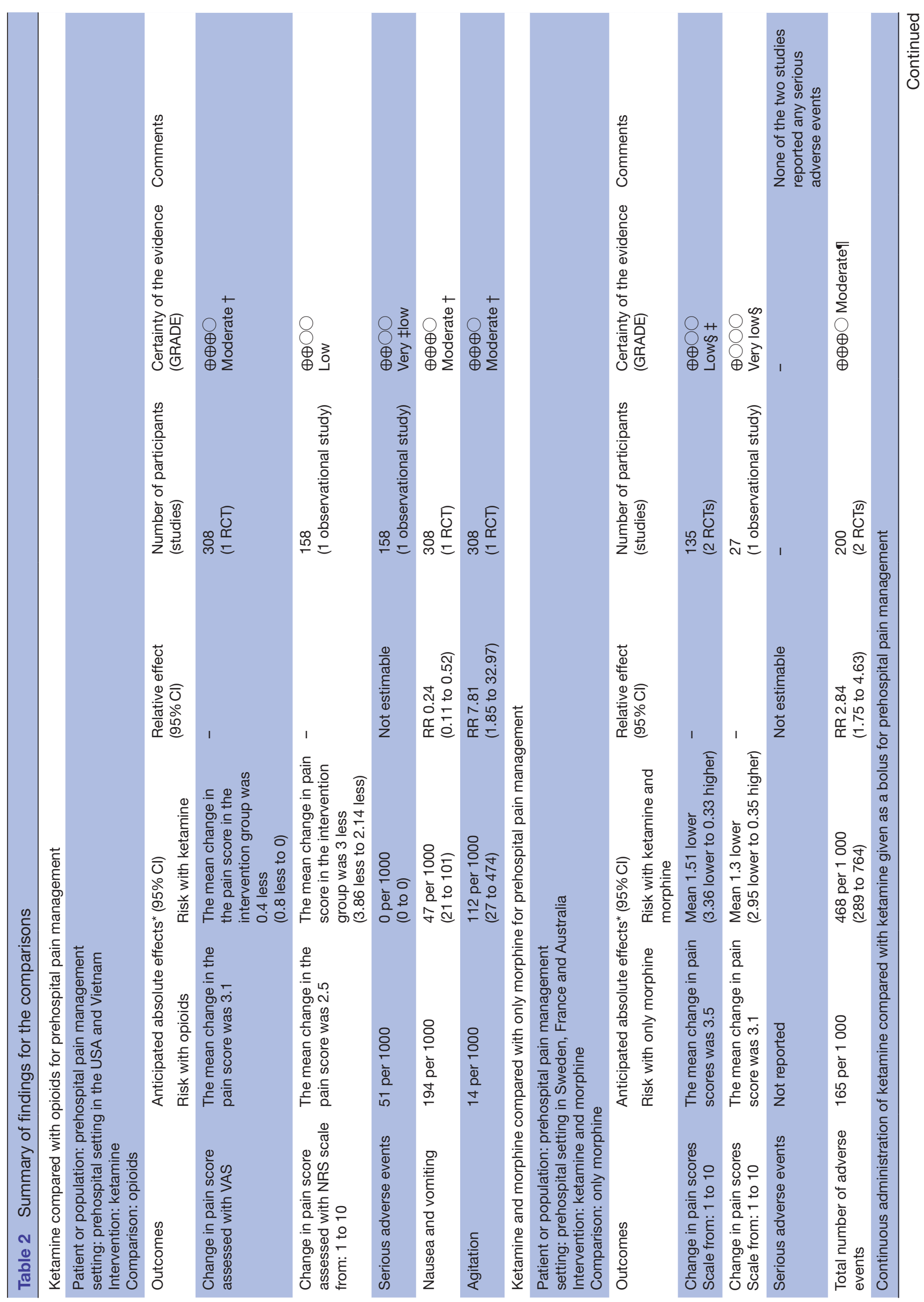




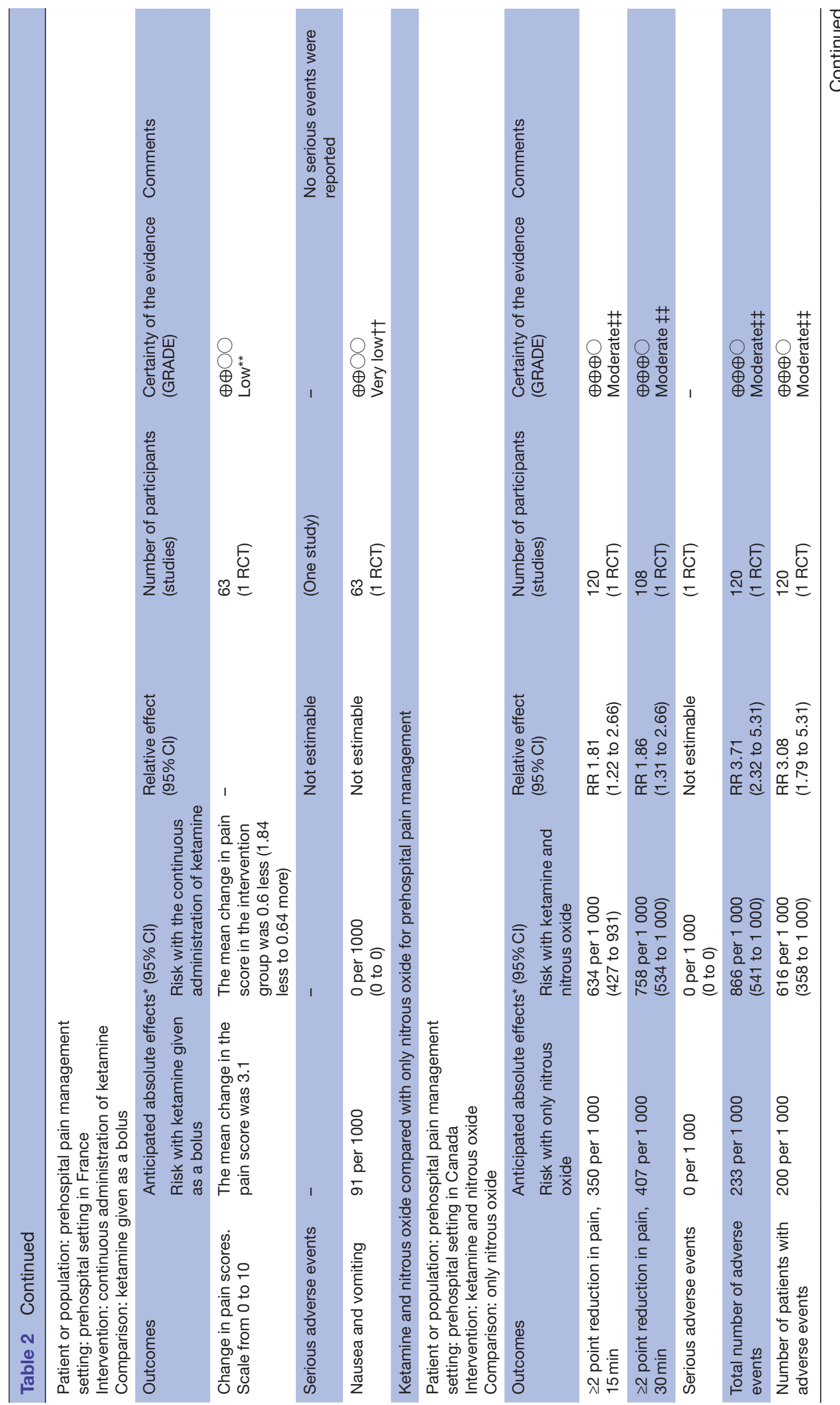

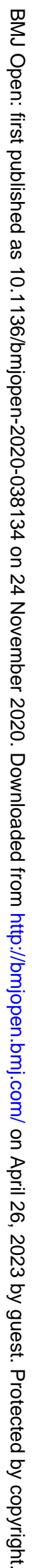




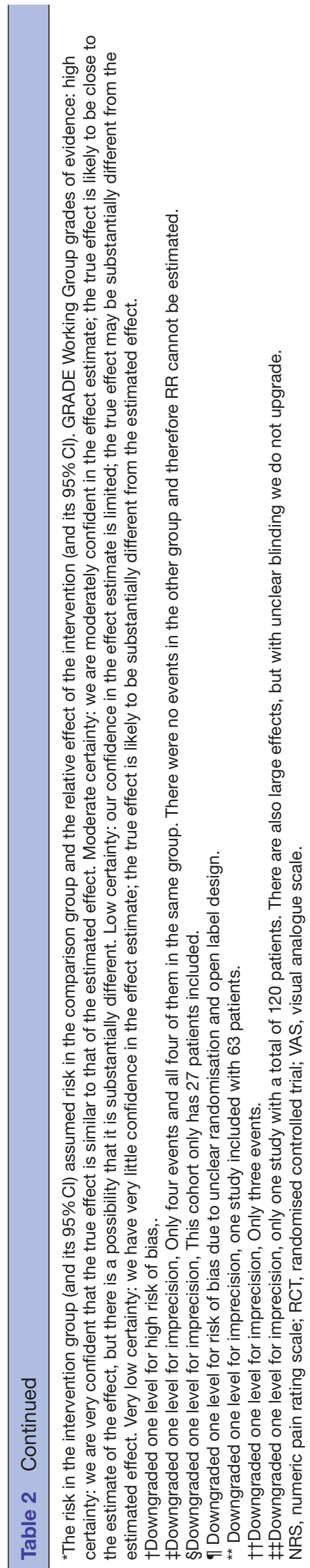

high risk of bias. However, there is moderate quality of the evidence for the main outcome, change in pain score, for one of the comparisons.

This systematic review has the benefit of systematic and transparent preplanned methodology. Decisions and judgements were conducted by two authors independently of each other, hence, reducing the risk of bias in the conduct of the review. We conducted a wide literature search in several databases, but it is still possible that there exist relevant studies that we did not identify, both in other databases and in other languages. As always with systematic reviews, there is the possibility that relevant studies may have been published after our search was conducted. Our deviation from the protocol to include a large study even though it included some children may be interpreted as a limitation. However, we would argue that the inclusion of extra patients (1876 patients added to the 884 patients from the other seven studies), where the large majority was adults adds greatly to the available information regarding side effects/adverse events.

Two of the studies were conducted in Iraq and in Vietnam, respectively, where a number of patients were injured in mine accidents. These studies were the largest studies and included 1909 patients. It is reasonable to assume that the results from studies conducted in war zones are not directly applicable in civilian settings since the victims tend to be men, relatively young and previously healthy and are not representative of trauma victims in general. The study from Iraq did not report on any of our predefined outcomes.

\section{Clinical implications}

Ketamine administered in analgesic doses $(0.1-0.2 \mathrm{mg} /$ $\mathrm{kg}$ ) intravenously appears to be at least as effective as opioids administered alone considering pain reduction. In the study from Iraq, an initial dose of ketamine $(0.2 \mathrm{mg} / \mathrm{kg})$ was given in all cases of penetrating trauma and burns, but patients with TBI or blunt injury received only pentazocine. ${ }^{19}$ The patients in the study conducted by Tran et al received $0.2-0.3 \mathrm{mg} / \mathrm{kg}$ intravenous of ketamine.$^{26}$ Four ${ }^{22-25}$ of the other five studies included studies administered ketamine in $0.2-0.3 \mathrm{mg} / \mathrm{kg}$ intravenous doses, while in the last intravenous study, ${ }^{20}$ the patients received $10-20 \mathrm{mg}$ intravenous. of ketamine. In the study where ketamine was administered intranasally, the patients received an average of $0.75 \mathrm{mg} / \mathrm{kg}$ of ketamine. ${ }^{21}$ Hence, the patients in all studies received appropriate analgesic doses of ketamine.

\section{Adverse events}

In general, very few adverse events were reported in the included studies. Most of the events were related to nausea and vomiting. Agitation was more common in the ketamine group in the study performed by Tran et $a l .{ }^{26}$ Bronsky et al reported that two patients experienced respiratory compromise and two suffered haemodynamic instability. ${ }^{25}$ All four patients were in the fentanyl group. 
Given the safety profile of ketamine and the results reported in the included studies, it appears reasonable to suggest that low-dose ketamine for analgesic purposes can be administered safely during prehospital emergency care when proper indications and contraindications are identified. Prehospital healthcare providers with a level of training suitable to administer ketamine-that is, personnel that are trained to handle potential adverse events-must be identified. None of the included studies had enough power to detect differences in rare events, and the quality of evidence was poor. One of the studies showed an increased number (pooled) of adverse events in the group receiving ketamine and morphine, indicating that an improved analgesic effect increases the risk for adverse events. It is unclear whether adverse events are more likely to occur with opioids than with ketamine. However, it is essential to note that this review describes ketamine administered in analgesic doses and not in sedative and anaesthetic doses where advanced skills are required to be able to handle the patient in an adequate manner.

\section{Studies from other settings}

In a recent systematic review and meta-analysis, Yousefifard et alincluded seven studies and pooled the effect estimates of observational and randomised interventional studies. ${ }^{29}$ They concluded that ketamine is an effective and safe medication in prehospital pain management in patients with trauma and can be considered as an acceptable alternative to opioids. The analgesic effect of low-dose ketamine is also employed in the hospital. In a recent systematic review and meta-analysis, Karlow et al studied ketamine as an alternative to opioids for acute pain in the emergency department (ED).$^{30}$ The authors concluded that ketamine can be used as an alternative to opioids in the ED, as they found that ketamine was non-inferior to opioids. They also found that the rate of non-severe adverse effects was higher with ketamine. It is unclear to what extent results from ED studies can be extrapolated to the prehospital setting. However, it is not obvious that the safety profile of ketamine in the prehospital setting is independent of the qualifications of the healthcare provider that administers the drug. Studies specifically addressing competence of prehospital providers administering ketamine should therefore be conducted. The body of evidence for benefit and possible harm is limited as few studies have been performed. Future studies need to address all relevant side effects, the optimal drug dose as well as all relevant outcome measures.

\section{CONCLUSION}

This systematic review of the current literature indicates that ketamine is an effective analgesic to be administered prehospitally.
Author affiliations

${ }^{1}$ Division of Prehospital Services, Air Ambulance Department, Oslo University Hospital, Oslo, Norway

${ }^{2}$ Faculty of Medicine, University of Oslo, Oslo, Norway

${ }^{3}$ Faculty of Health Sciences, University of Stavanger, Stavanger, Norway

${ }^{4}$ Department of Research, Norwegian Air Ambulance Foundation, Oslo, Norway

${ }^{5}$ Trauma Unit, Sørlandet Hospital, Kristiansand, Norway

${ }^{6}$ Department of Prehospital Care and Disaster Medicine, Region of Skåne, Lund, Sweden

${ }^{7}$ Research Department, Prehospital Emergency Medical Service, Central Denmark Region, Aarhus, Denmark

${ }^{8}$ Department of Anaesthesiology, Regional Hospital of Horsens, Horsens, Denmark ${ }^{9}$ Centre for Prehospital Emergency Care, Oulu University Hospital, Oulu, Finland

${ }^{10}$ Anaesthesia Research group, MRC, Oulu University Hospital and University of Oulu, Oulu, Finland

${ }^{11}$ Department of Anaesthesiology and Intensive Care, Linköping University Hospital, Linköping, Sweden

${ }^{12}$ Department of Biomedical and Clinical Sciences, Linköping University, Linköping, Sweden

${ }^{13}$ Landspitalinn University Hospital, Reykjavik, Iceland

${ }^{14}$ Danish Air Ambulance, Aarhus, Denmark

${ }^{15}$ Department of Anaesthesiology, Aarhus University Hospital, Aarhus, Denmark

${ }^{16}$ Department of Clinical Medicine, Aarhus University, Aarhus, Denmark

${ }^{17}$ Centre for Prehospital Emergency Medicine, Kuopio University Hospital, Kuopio, Finland

${ }^{18}$ University of Eastern Finland, Kuopio, Finland

${ }^{19}$ Division for Health Services, Norwegian Institute of Public Health, Oslo, Norway

Acknowledgements We thank research librarian Jane Kjemtrup Andersen (Viborg Regional Hospital, Denmark) for developing the search strategies.

Contributors MS supervised the process of drafting this manuscript and coordinated all identification, data extraction and appraisal of included manuscripts MS and either PKH, MR or PK independently assessed all potential eligible articles for inclusion. GEV coordinated all methodological support. MS, PKH, PK, KDF, $\mathrm{LR}, \mathrm{RL}, \mathrm{VM}, \mathrm{LR}, \mathrm{JK}, \mathrm{MR}, \mathrm{GEV}$ are members of the SSAl task force on prehospital pain management and participated in planning, design, interpretation of results, manuscript drafting and revisions of the manuscript.

Funding SSAl funded meetings and software costs. The Norwegian Air Ambulance Foundation funded publication costs. Otherwise this research received no further grant from any funding agency in the public, commercial or not-for-profit sectors.

Competing interests None declared.

Patient consent for publication Not required.

Provenance and peer review Not commissioned; externally peer reviewed. Data availability statement No data are available.

Supplemental material This content has been supplied by the author(s). It has not been vetted by BMJ Publishing Group Limited (BMJ) and may not have been peer-reviewed. Any opinions or recommendations discussed are solely those of the author(s) and are not endorsed by BMJ. BMJ disclaims all liability and responsibility arising from any reliance placed on the content. Where the content includes any translated material, BMJ does not warrant the accuracy and reliability of the translations (including but not limited to local regulations, clinical guidelines, terminology, drug names and drug dosages), and is not responsible for any error and/or omissions arising from translation and adaptation or otherwise.

Open access This is an open access article distributed in accordance with the Creative Commons Attribution Non Commercial (CC BY-NC 4.0) license, which permits others to distribute, remix, adapt, build upon this work noncommercially, and license their derivative works on different terms, provided the original work is properly cited, appropriate credit is given, any changes made indicated, and the use is non-commercial. See: http://creativecommons.org/ licenses/by-nc/4.0/.

\section{ORCID iDs}

Lasse Raatiniemi http://orcid.org/0000-0001-5537-9749

Leif Rognås http://orcid.org/0000-0002-2542-565X

Marius Rehn http://orcid.org/0000-0001-9519-241X 


\section{REFERENCES}

1 Jennings PA, Cameron P, Bernard S. Epidemiology of prehospital pain: an opportunity for improvement. Emerg Med J 2011;28:530-1.

2 Albrecht E, Taffe P, Yersin B, et al. Undertreatment of acute pain (oligoanalgesia) and medical practice variation in prehospital analgesia of adult trauma patients: a $10 \mathrm{yr}$ retrospective study. $\mathrm{Br} \mathrm{J}$ Anaesth 2013;110:96-106.

3 Galinski M, Ruscev M, Gonzalez G, et al. Prevalence and management of acute pain in prehospital emergency medicine. Prehosp Emerg Care 2010;14:334-9.

4 Bounes V, Barniol C, Minville V, et al. Predictors of pain relief and adverse events in patients receiving opioids in a prehospital setting. Am J Emerg Med 2011;29:512-7.

5 Lodge D, Anis NA, Burton NR. Effects of optical isomers of ketamine on excitation of cat and rat spinal neurones by amino acids and acetylcholine. Neurosci Lett 1982;29:281-6.

6 Craven R. Ketamine. Anaesthesia 2007;62 Suppl 1:48-53.

7 Green SM, Johnson NE. Ketamine sedation for pediatric procedures: Part 2, review and implications. Ann Emerg Med 1990;19:1033-46.

8 Bourgoin A, Albanèse J, Léone $\mathrm{M}$, et al. Effects of sufentanil or ketamine administered in target-controlled infusion on the cerebral hemodynamics of severely brain-injured patients. Crit Care Med 2005;33:1109-13.

9 Bourgoin A, Albanèse J, Wereszczynski N, et al. Safety of sedation with ketamine in severe head injury patients: comparison with sufentanil. Crit Care Med 2003;31:711-7.

10 Albanèse J, Arnaud S, Rey M, et al. Ketamine decreases intracranial pressure and electroencephalographic activity in traumatic brain injury patients during propofol sedation. Anesthesiology 1997;87:1328-34.

11 Bar-Joseph G, Guilburd Y, Tamir A, et al. Effectiveness of ketamine in decreasing intracranial pressure in children with intracranial hypertension. J Neurosurg Pediatr 2009;4:40-6.

12 Sherwin TS, Green SM, Khan A, et al. Does adjunctive midazolam reduce recovery agitation after ketamine sedation for pediatric procedures? A randomized, double-blind, placebo-controlled trial. Ann Emerg Med 2000;35:229-38.

13 McManus JG, Sallee DR. Pain management in the prehospital environment. Emerg Med Clin North Am 2005;23:415-31.

14 Kennedy RM, Porter FL, Miller JP, et al. Comparison of fentanyl/ midazolam with ketamine/midazolam for pediatric orthopedic emergencies. Pediatrics 1998;102:956-63.

15 McGuinness SK, Wasiak J, Cleland H, et al. A systematic review of ketamine as an analgesic agent in adult burn injuries. Pain Med 2011;12:1551-8.
16 Bonanno FG. Ketamine in war/tropical surgery (a final tribute to the racemic mixture). Injury 2002;33:323-7.

17 Higgins JPT, Green S. Cochrane handbook for systematic reviews of interventions. The Cochrane Collaboration, 2011.

18 Atkins D, Best D, Briss PA, et al. Grading quality of evidence and strength of recommendations. BMJ 2004;328:1490-7.

19 Losvik OK, Murad MK, Skjerve E, et al. Ketamine for prehospital trauma analgesia in a low-resource rural trauma system: a retrospective comparative study of ketamine and opioid analgesia in a ten-year cohort in Iraq. Scand J Trauma Resusc Emerg Med 2015;23:94

20 Jennings PA, Cameron P, Bernard S, et al. Morphine and ketamine is superior to morphine alone for out-of-hospital trauma analgesia: a randomized controlled trial. Ann Emerg Med 2012;59:497-503.

21 Andolfatto $\mathrm{G}$, Innes K, Dick W, et al. Prehospital analgesia with intranasal ketamine (PAIN-K): a randomized double-blind trial in adults. Ann Emerg Med 2019;74:241-50.

22 Wiel E, Zitouni D, Assez N, et al. Continuous infusion of ketamine for out-of-hospital isolated orthopedic injuries secondary to trauma: a randomized controlled trial. Prehosp Emerg Care 2015;19:10-16.

23 Galinski M, Dolveck F, Combes X, et al. Management of severe acute pain in emergency settings: ketamine reduces morphine consumption. Am J Emerg Med 2007;25:385-90.

24 Johansson P, Kongstad P, Johansson A. The effect of combined treatment with morphine sulphate and low-dose ketamine in a prehospital setting. Scand J Trauma Resusc Emerg Med 2009;17:61.

25 Bronsky ES, Koola C, Orlando A, et al. Intravenous low-dose ketamine provides greater pain control compared to fentanyl in a civilian prehospital trauma system: a propensity matched analysis. Prehosp Emerg Care 2019;23:1-8.

26 Tran KP, Nguyen Q, Truong XN, et al. A comparison of ketamine and morphine analgesia in prehospital trauma care: a cluster randomized clinical trial in rural Quang tri Province, Vietnam. Prehosp Emerg Care 2014;18:257-64.

27 Champion HR, Sacco WJ, Copes WS, et al. A revision of the trauma score. J Trauma 1989;29:623-9.

28 Johansson J, Sjöberg J, Nordgren M, et al. Prehospital analgesia using nasal administration of S-ketamine--a case series. Scand J Trauma Resusc Emerg Med 2013;21:38.

29 Yousefifard M, Askarian-Amiri S, Rafiei Alavi SN, et al. The efficacy of ketamine administration in prehospital pain management of trauma patients; a systematic review and meta-analysis. Arch Acad Emerg Med 2020;8:e1.

30 Karlow N, Schlaepfer CH, Stoll CRT, et al. A systematic review and meta-analysis of ketamine as an alternative to opioids for acute pain in the emergency department. Acad Emerg Med 2018;25:1086-97. 